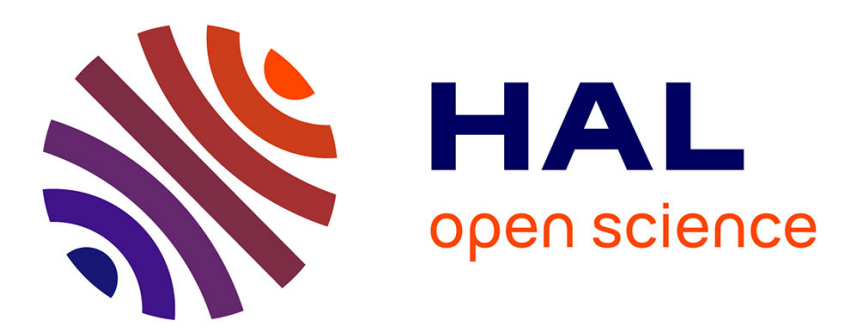

\title{
The chemical composition of impact craters on Titan
}

A. Solomonidou, C. Neish, A. Coustenis, M. Malaska, Alice Le Gall, R. M. C. Lopes, A. Werynski, Y. Markonis, K. Lawrence, N. Altobelli, et al.

\section{To cite this version:}

A. Solomonidou, C. Neish, A. Coustenis, M. Malaska, Alice Le Gall, et al.. The chemical composition of impact craters on Titan. Astronomy and Astrophysics - A\&A, 2020, 641, A16 (14 p.). 10.1051/0004-6361/202037866 . insu-02929791

\section{HAL Id: insu-02929791 https://hal-insu.archives-ouvertes.fr/insu-02929791}

Submitted on 16 Nov 2020

HAL is a multi-disciplinary open access archive for the deposit and dissemination of scientific research documents, whether they are published or not. The documents may come from teaching and research institutions in France or abroad, or from public or private research centers.
L'archive ouverte pluridisciplinaire HAL, est destinée au dépôt et à la diffusion de documents scientifiques de niveau recherche, publiés ou non, émanant des établissements d'enseignement et de recherche français ou étrangers, des laboratoires publics ou privés. 


\title{
The chemical composition of impact craters on Titan
}

\section{Implications for exogenic processing}

\author{
A. Solomonidou ${ }^{1,2,3}$, C. Neish ${ }^{4}$, A. Coustenis ${ }^{2}$, M. Malaska ${ }^{5}$, A. Le Gall ${ }^{6,7}$, R. M. C. Lopes ${ }^{5}$, A. Werynski ${ }^{4}$,
} Y. Markonis ${ }^{3}$, K. Lawrence ${ }^{5}$, N. Altobelli ${ }^{1}$, O. Witasse ${ }^{8}$, A. Schoenfeld ${ }^{9}$, C. Matsoukas ${ }^{10}$, I. Baziotis ${ }^{11}$, and P. Drossart ${ }^{2}$

${ }^{1}$ European Space Agency (ESA), European Space Astronomy Centre (ESAC), Villanueva de la Canada, Madrid, Spain e-mail: anezina. solomonidou@esa.int

${ }^{2}$ LESIA - Observatoire de Paris, CNRS, UPMC Univ. Paris 06, Univ. Paris-Diderot, Meudon, France e-mail: athena. coustenis@obspm. fr

${ }^{3}$ Faculty of Environmental Sciences, Czech University of Life Sciences Prague, Suchdol, 16500, Praha, Czech Republic

${ }^{4}$ Department of Earth Sciences, The University of Western Ontario, London, ON N6A 5B7, Canada e-mail: cneish@uwo.ca

5 Jet Propulsion Laboratory, California Institute of Technology, Pasadena, California, USA

${ }^{6}$ LATMOS/IPSL, UVSQ Université Paris-Saclay, Sorbonne Université, CNRS, France

${ }^{7}$ Institut Universitaire de France (IUF), Paris, France

${ }^{8}$ European Space Agency (ESA), European Space Research and Technology Center (ESTEC), Noordwijk, The Netherlands

9 Department of Earth, Planetary, and Space Sciences, University of California, Los Angeles, CA, USA

${ }^{10} \mathrm{KTH}-$ Royal Institute of Technology, Stockholm, Sweden

${ }^{11}$ Agricultural University of Athens, Mineral Resources and Agricultural Engineering, Iera Odos str. 75, 11855 Athens, Greece

Received 2 March 2020 / Accepted 29 July 2020

\begin{abstract}
We investigate the spectral behavior of nine Titan impact craters in order to constrain their composition. Past studies that have examined the chemical composition of impact craters on Titan have either used qualitative comparisons between craters or combined all craters into a single unit, rather than separating them by geographic location and/or degradation state. Here, we use Visual and Infrared Mapping Spectrometer (VIMS) data and a radiative transfer code to estimate the atmospheric contribution to the data, extract the surface albedos of the impact craters, and constrain their composition by using a library of candidate Titan materials, including essentially water ice, tholin, a dark component, and other possible ices at different grain sizes. Following a general characterization of the impact craters, we study two impact crater subunits, the "crater floor" and the "ejecta blanket". The results show that the equatorial dune craters - Selk, Ksa, Guabonito, and the crater on Santorini Facula - appear to be purely composed of organic material (mainly an unknown dark component). Titan's midlatitude plain craters - Afekan, Soi, and Forseti - along with Menrva and Sinlap, are enriched in water ice within an organic-based mixture. This follows the geographic pattern observed in our previous work with VIMS data, where the uppermost layers of the midlatitude alluvial fans, undifferentiated plains, and labyrinth terrains were found to consist of a mixture of organics and water ice, while the equatorial plains, hummocky terrains, and dunes were found to consist of a mixture of dark material and tholins. Furthermore, we found that the addition of some form of ice improves the fit in the ejecta spectra of Afekan and Sinlap craters. We find no indication for the presence of either $\mathrm{NH}_{3}$ or $\mathrm{CO}_{2}$ ice. Our main results agree with an existing Titan surface evolution scenario, wherein the impact cratering process produces a mixture of organic material and water ice, which is later "cleaned" through fluvial erosion in the midlatitude plains. This cleaning process does not appear to operate in the equatorial regions, which are quickly covered by a thin layer of sand sediment (with the exception of the freshest crater on Titan, Sinlap). Thus, it appears that active processes are working to shape the surface of Titan, and it remains a dynamic world in the present day.
\end{abstract}

Key words. planets and satellites: composition - planets and satellites: dynamical evolution and stability - radiative transfer planets and satellites: surfaces - planets and satellites: general - techniques: imaging spectroscopy

\section{Introduction}

After 13 years of exploration by the Cassini-Huygens mission, Saturn's moon Titan was shown to possess unique properties, such as its Earth-like atmospheric structure and composition, in addition to its surface geology. Geomorphological features commonly found on Earth, such as mountains, drainage networks, dunes, and lakes, were observed on Titan by the Cassini spacecraft and the Huygens probe (e.g., Tomasko et al. 2005; Lopes et al. 2019, 2020). One additional similarity with Earth's geology is the limited number of impact craters on Titan's surface, unlike the heavily cratered surfaces of the other Saturnian satellites.
It is thought that erosional processes similar to those on Earth have obscured the majority of impact craters that have hit the surface in the past (Neish et al. 2013, 2016), especially in the polar regions (Neish \& Lorenz 2014), leaving only 90 potential features that could be craters (Lorenz et al. 2007; Wood et al. 2010; Buratti et al. 2012; Neish \& Lorenz 2012; Hedgepeth et al. 2020).

Understanding the compositional nature of impact craters informs us both about Titan's interior and the atmospheric influence on its surface. Indeed, impact craters are one of the few geologic features that expose material from the interior, providing a rare opportunity to understand the subsurface composition 
of Titan. In comparison, the Cassini RADAR instrument was only capable of penetrating a meter into the organic sediments that blanket much of Titan's surface (Janssen et al. 2016). Impact craters also give us a unique opportunity to study weathering on the surface of Titan. We can quantify how craters erode over time by calculating their depths, and comparing them to unweathered impact craters from similarly sized icy satellites like Ganymede (Neish et al. 2013; Hedgepeth et al. 2020). Erosional processes on Titan are likely to differ across its surface, with more aeolian modification near the equator and more fluvial modification near the poles. By examining the compositional and morphologic differences between the craters, we can determine if and how the craters' evolution depends on their geographic location on Titan. In this study, we examine nine Titan impact craters by combining Visual and Infrared Mapping Spectrometer (VIMS) data and Titan Radar Mapper (RADAR) data and by applying a radiative transfer (RT) code (e.g., Hirtzig et al. 2013) to infer their composition.

A study by Werynski et al. (2019) provided a compositional analysis of Titan's impact craters using qualitative comparisons between simple Cassini VIMS Red Green Blue (RGB) composites and microwave emissivity data from the Cassini RADAR instrument (Janssen et al. 2016). This provided a sense of the first order compositional differences between Titan's impact craters. Here, we extend that work by quantifying the atmospheric contributions present in the VIMS data, extracting the craters' actual surface albedos, and providing compositional fits to the data assuming basic Titan materials, such as organic aerosols, water ice, a dark material that is expected to be organic (Solomonidou et al. 2018), and other ices. The aim of this work is to constrain the spectral behavior and composition of impact craters in different geographic locations on Titan. From this new information, we look for evidence to constrain existing scenarios for the evolution of Titan's surface.

\section{Data and observations}

The crater selection was performed based on VIMS data availability, as well as data parameter criteria such as observational geometry conditions and spatial resolution. Past studies that have looked at the chemical composition of impact craters have either used qualitative comparisons between craters (e.g., Neish et al. 2015; Werynski et al. 2019) or combined all craters into a single unit, rather than separating them by geographic location or degradation state (Solomonidou et al. 2018). Here, we used the RT model to first estimate the atmospheric contribution to the data, then extracted the surface albedos of the impact crater subunits, and finally, constrained their composition by using a library of reflectance spectra candidate Titan materials. Similar information has been obtained in the past but only for a subset of impact craters on Titan (Selk, Sinlap, Soi, Afekan, Forseti, and Menrva) and only for their ejecta blankets (Solomonidou et al. 2018). Here, we expand on that initial study, utilizing a larger number of craters, determining the composition of both the craters' ejecta blankets and their interiors (including new information on nine crater floors and three additional ejecta blankets), and separating them by geographic units. We define two impact crater subunits: the "crater floor" (which refers to the bottom of a crater depression) and the "ejecta blanket" (which is the material ejected from the transient crater during an impact event) (e.g., Melosh 1989; Lorenz et al. 2007; Malaska et al. 2016; Neish et al. 2016).

From the 90 potential impact craters on Titan, only 38 are labeled as "certain" or "nearly certain" (Hedgepeth et al. 2020), while the rest are labeled as "probable" or "possible." According to Wood et al. (2010) and Hedgepeth et al. (2020), the characterization of craters as certain, nearly certain, probable, or possible is based on how many lines of evidence there are to support the feature's identification as an impact crater (e.g., circularity, ejecta blanket, rims, and dark crater floors). For instance, a circular feature with the presence of an ejecta blanket, a rim, and dark floors, is considered a certain Titan impact crater. A circular feature with no clear rim or ejecta blanket is considered a probable or possible impact crater. From the nine certain or nearly certain impact craters we have selected for this study, six of them are found in the equatorial dunes fields (up to $20^{\circ} \mathrm{N}-\mathrm{S}$ ) and three of them are found in the midlatitude plains $\left(\geq 20^{\circ} \mathrm{N}-\mathrm{S}\right)$ (Fig. 1). We call the former "dune craters" and the latter "plain craters". We note that Titan is dominated by plain $(65 \%)$ and dune fields (17\%) (Lopes et al. 2020), with the vast majority of craters concentrated in the equatorial dunes and midlatitude plains (only $8 \%$ of certain or nearly certain impact craters are located poleward of $50^{\circ}$ ) (Neish \& Lorenz 2014; Hedgepeth et al. 2020). Our selected craters are presented in Table 1 and shown in Figs. 1 and 2.

Figure 1 includes maps of the different views of Titan's surface taken from different instruments at different wavelengths, with the locations of the nine craters we analyzed in this study marked. Panel a shows a VIMS RGB color map (R: 1.59/1.27 $\mu \mathrm{m}$, G: $2.03 / 1.27 \mu \mathrm{m}, \mathrm{B}: 1.27 / 1.08 \mu \mathrm{m})$, with the selected crater floors and the ejecta blankets. In this image, brown areas are representative of sand dunes, bright areas are representative of plains, and blue areas are thought to be enriched in water ice. The rest of the panels show: (b) the map of Synthetic Aperture Radar (SAR) swaths, (c) the emissivity map that is used to constrain the composition of the various craters (Janssen et al. 2016), and (d) the craters as shown on Titan's major geomorphological map (Lopes et al. 2020). On Titan, lower emissivity values are thought to indicate an enrichment in water ice, while higher emissivity values are consistent with an organic-rich layer. Figure 2 shows the VIMS datacubes in RGB mode (R: $5.00 \mu \mathrm{m}, \mathrm{G}: 2.03 \mu \mathrm{m}, \mathrm{B}: 1.27 \mu \mathrm{m})$ that were used in the selection of pixels for the crater floor and ejecta blanket units. The method with which the regions of interest were selected is described in Sect. 3 .

\section{Method of analysis}

Our ultimate goal is to examine two different geologic subunits for impact craters on Titan (i.e., crater floors and ejecta blankets) present in two different geographic regions (i.e., dunes and plains). For this work, we use VIMS data, an RT code, and a library of candidate Titan constituents. This library has been shown to offer good constraints on the chemical composition of Titan's surface regions (e.g., Solomonidou et al. 2018). In this section, we describe the methods we used is our data analysis.

\subsection{VIMS pixel selection}

The pixel selections shown in Fig. 2 were made using overlapping images of SAR and VIMS data, which helped in locating the pixels corresponding to the specific crater floor and ejecta blanket areas. The method of VIMS-SAR superposition and pixel selection we used is described in detail in Solomonidou et al. (2014, 2018, 2020). The applications and tools used are provided by the US Geological Survey's (USGS) Integrated Software for Imagers and Spectrometers 3 (ISIS3) program ${ }^{1}$.

https://isis.astrogeology.usgs.gov 
A. Solomonidou et al.: The chemical composition of impact craters on Titan. I.
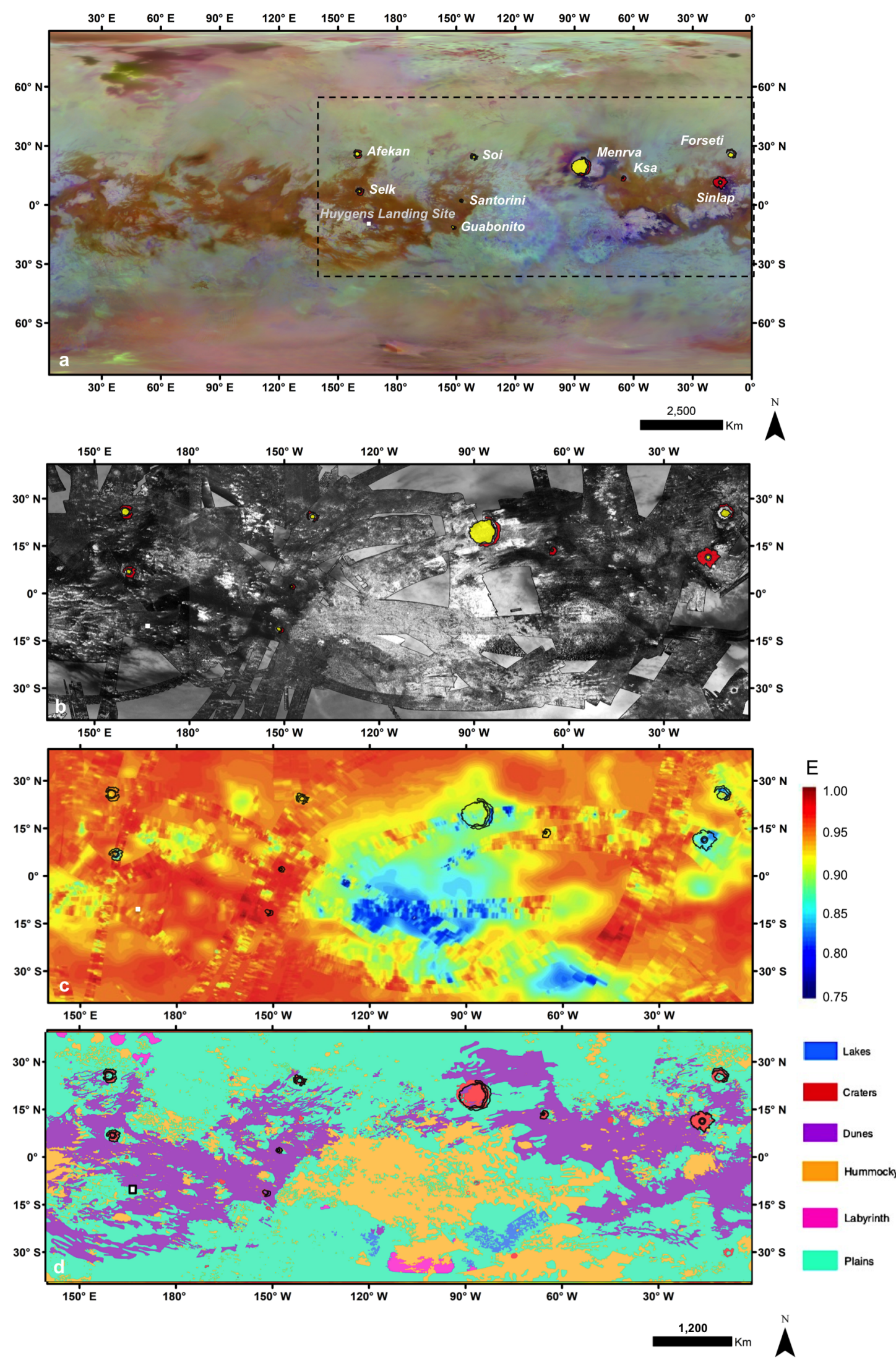

Fig. 1. Dune and plain impact craters on Titan's surface with (a) VIMS RGB color map background (R:1.59/1.27, G: 2.03/1.27, and B: 1.27/1.08 $\mu \mathrm{m}$ ratios) (Le Mouélic et al. 2019); (b) SAR background (NASA/JPL/Cassini RADAR team); (c) Microwave emissivity map background (Janssen et al. 2016); $(d)$ Titan's major geomorphological units (Lopes et al. 2020). For $(a)$ and $(b)$, yellow selections correspond to the crater floor, and red selections to the ejecta blanket. The black dashed rectangle in $(a)$ corresponds to the zoomed areas shown in $b, c$, and $d$. The Huygens landing site is marked with a white box. 
Table 1. Observational details of the nine craters examined in this work.

\begin{tabular}{|c|c|c|c|c|}
\hline Name & $\begin{array}{c}\text { VIMS } \\
\text { (flyby-date) }\end{array}$ & $\begin{array}{c}\text { RADAR } \\
\text { (flyby-date) }\end{array}$ & $\begin{array}{c}\text { Crater floor } \\
\text { Coordinates } \\
\text { Geometry-Resolution } \\
(i, e, \alpha, \text { res }) \\
\end{array}$ & $\begin{array}{c}\text { Ejecta blanket } \\
\text { Coordinates } \\
\text { Geometry-Resolution } \\
(i, e, \alpha, \text { res }) \\
\end{array}$ \\
\hline \multicolumn{5}{|l|}{ Dune craters } \\
\hline Ksa & T125 (11/2016) & T77 (06/2011) & $\begin{array}{c}14.2^{\circ} \mathrm{N}-65.4^{\circ} \mathrm{W} \\
41^{\circ} / 41^{\circ} / 68^{\circ} / 22 \mathrm{~km}\end{array}$ & $\begin{array}{c}15^{\circ} \mathrm{N}-64.9^{\circ} \mathrm{W} \\
41^{\circ} / 41^{\circ} / 68^{\circ} / 22 \mathrm{~km}\end{array}$ \\
\hline Selk & T40 (01/2008) & $\begin{array}{l}\text { T36 (10/2007) } \\
\text { T95 (10/2013) }\end{array}$ & $\begin{array}{c}6.7^{\circ} \mathrm{N}-160.7^{\circ} \mathrm{W} \\
34^{\circ} / 12^{\circ} / 40^{\circ} / 04 \mathrm{~km}\end{array}$ & $\begin{array}{c}7.5^{\circ} \mathrm{N}-161.7^{\circ} \mathrm{W} \\
35^{\circ} / 12^{\circ} / 39^{\circ} / 04 \mathrm{~km}\end{array}$ \\
\hline Santorini & T113 (09/2015) & $\begin{array}{l}\text { T56 (06/2009) } \\
\text { T44 (05/2008) }\end{array}$ & $\begin{array}{c}2^{\circ} \mathrm{N}-157.2^{\circ} \mathrm{W} \\
56^{\circ} / 02^{\circ} / 57^{\circ} / 14 \mathrm{~km}\end{array}$ & $\begin{array}{c}1.4^{\circ} \mathrm{N}-146^{\circ} \mathrm{W} \\
55^{\circ} / 02^{\circ} / 57^{\circ} / 14 \mathrm{~km}\end{array}$ \\
\hline Guabonito & T113 (09/2015) & $\begin{array}{l}\text { T13 (04/2006) } \\
\text { T48 (12/2008) }\end{array}$ & $\begin{array}{c}11.4^{\circ} \mathrm{N}-151.8^{\circ} \mathrm{W} \\
65^{\circ} / 14^{\circ} / 53^{\circ} / 10 \mathrm{~km}\end{array}$ & $\begin{array}{c}12.1^{\circ} \mathrm{N}-152.1^{\circ} \mathrm{W} \\
65^{\circ} / 16^{\circ} / 53^{\circ} / 10 \mathrm{~km}\end{array}$ \\
\hline $\operatorname{Menrva}^{(*)}$ & T114 (11/2015) & $\begin{array}{l}\text { T3 }(02 / 2005) \\
\text { T77 }(06 / 2011)\end{array}$ & $\begin{array}{c}20.5^{\circ} \mathrm{N}-86.4^{\circ} \mathrm{W} \\
46^{\circ} / 36^{\circ} / 60^{\circ} / 08 \mathrm{~km}\end{array}$ & $\begin{array}{c}17.7^{\circ} \mathrm{N}-83.1^{\circ} \mathrm{W} \\
43^{\circ} / 33^{\circ} / 60^{\circ} / 08 \mathrm{~km}\end{array}$ \\
\hline Sinlap & T110 (03/2015) & $\begin{array}{c}\text { T3 }(02 / 2005) \\
\text { T17 }(09 / 2006) \\
\text { T108 }(01 / 2015)\end{array}$ & $\begin{array}{c}11.5^{\circ} \mathrm{N}-15.7^{\circ} \mathrm{W} \\
28^{\circ} / 07^{\circ} / 35^{\circ} / 09 \mathrm{~km}\end{array}$ & $\begin{array}{c}10.9^{\circ} \mathrm{N}-17.2^{\circ} \mathrm{W} \\
30^{\circ} / 05^{\circ} / 34^{\circ} / 09 \mathrm{~km}\end{array}$ \\
\hline \multicolumn{5}{|l|}{ Plain craters } \\
\hline Forseti & T13 (04/2016) & $\begin{array}{c}\text { T23 }(01 / 2007) \\
\text { T84 }(06 / 2012) \\
\text { T113 }(09 / 2015)\end{array}$ & $\begin{array}{c}25.7^{\circ} \mathrm{N}-11.1^{\circ} \mathrm{W} \\
51^{\circ} / 27^{\circ} / 37^{\circ} / 10 \mathrm{~km}\end{array}$ & $\begin{array}{c}25.6^{\circ} \mathrm{N}-10.9^{\circ} \mathrm{W} \\
51^{\circ} / 27^{\circ} / 37^{\circ} / 10 \mathrm{~km}\end{array}$ \\
\hline Afekan & T38 (12/2007) & $\begin{array}{l}\text { T43 }(05 / 2008) \\
\text { T83 }(05 / 2012)\end{array}$ & $\begin{array}{c}25.6^{\circ} \mathrm{N}-200^{\circ} \mathrm{W} \\
44^{\circ} / 24^{\circ} / 42^{\circ} / 16 \mathrm{~km}\end{array}$ & $\begin{array}{c}25.3^{\circ} \mathrm{N}-201^{\circ} \mathrm{W} \\
44^{\circ} / 24^{\circ} / 42^{\circ} / 16 \mathrm{~km}\end{array}$ \\
\hline Soi & T12 (03/2016) & $\begin{array}{l}\text { T16 }(07 / 2006) \\
\text { T55 }(05 / 2009) \\
\text { T56 }(06 / 2009)\end{array}$ & $\begin{array}{c}24.2^{\circ} \mathrm{N}-141.2^{\circ} \mathrm{W} \\
44^{\circ} / 26^{\circ} / 23^{\circ} / 46 \mathrm{~km}\end{array}$ & $\begin{array}{c}24.6^{\circ} \mathrm{N}-142.2^{\circ} \mathrm{W} \\
44^{\circ} / 26^{\circ} / 23^{\circ} / 46 \mathrm{~km}\end{array}$ \\
\hline Titan Units & & & Centroid Coordinates & VIMS \\
\hline $\begin{array}{l}\text { Undifferentiated plain } \\
\text { (NE of Soi crater) }\end{array}$ & T08 (10/2005) & T55 (05/2009) & $30.4^{\circ} \mathrm{N}-133.3^{\circ} \mathrm{W}$ & $\begin{array}{c}(i, e, \alpha, \text { res }) \\
51^{\circ} / 34^{\circ} / 23^{\circ} / 75 \mathrm{~km}\end{array}$ \\
\hline $\begin{array}{c}\text { Dunes } \\
\text { (Belet field) }\end{array}$ & T65 (01/2010) & T92 (07/2013) & $5^{\circ} \mathrm{N}-237^{\circ} \mathrm{W}$ & $43^{\circ} / 23^{\circ} / 43^{\circ} / 91 \mathrm{~km}$ \\
\hline
\end{tabular}

Notes. In addition, we have included two typical Titan regions (i.e., an undifferentiated plain and a dune field) from Solomonidou et al. (2016, 2018) for context purposes. Here we report the related Flybys ("T" stands for Cassini Flybys of Titan) and dates for the VIMS and RADAR data used in this work, the center coordinates of the two units of interest (crater floors and ejecta blankets), and geometry details (angles of Incidence (i), Emission $(e)$, Phase $(\alpha)$, and Spatial Resolution (res)) of the VIMS cubes. ${ }^{(*)}$ Menrva straddles the dune and the plain regions.

These include tools for importing the data into ISIS3 and map projecting them. In the latter step, we upsampled the original VIMS image at $2.03 \mu \mathrm{m}$ (a process of artificially increasing the resolution by resizing the image). In addition, in order to match the map projection and spatial resolution of VIMS images to the SAR images, we projected the original VIMS images at $2.03 \mu \mathrm{m}$ using a cubic convolution interpolation. Figure 3 shows an example for the Sinlap crater floor and ejecta blanket pixel selections.

\subsection{VIMS analysis}

VIMS has 256 infrared (IR) bands, but there are only seven "methane windows" in Titan's atmosphere where the methane absorption is minimal, and thus the surface can be observed. These windows are centered at $0.93,1.08,1.27,1.59,2.03,2.69$ 2.79, and $5.00 \mu \mathrm{m}$ (e.g., Sotin et al. 2005; Soderblom et al. 2007). At these wavelengths, the methane absorption is weaker but still present (Hirtzig et al. 2013) and scattering by haze particles is not negligible, especially at the shortest wavelengths. Hence, extracting information about the lower atmosphere and the surface of Titan from near-IR spectra requires a good understanding of the methane and haze contributions to the opacity. For this reason, we use a RT code whose characteristics, methodology, and several applications on VIMS data are presented in Hirtzig et al. (2013), Lopes et al. (2016), Malaska et al. (2020) and Solomonidou et al. (2014, 2016, 2018, 2020). 

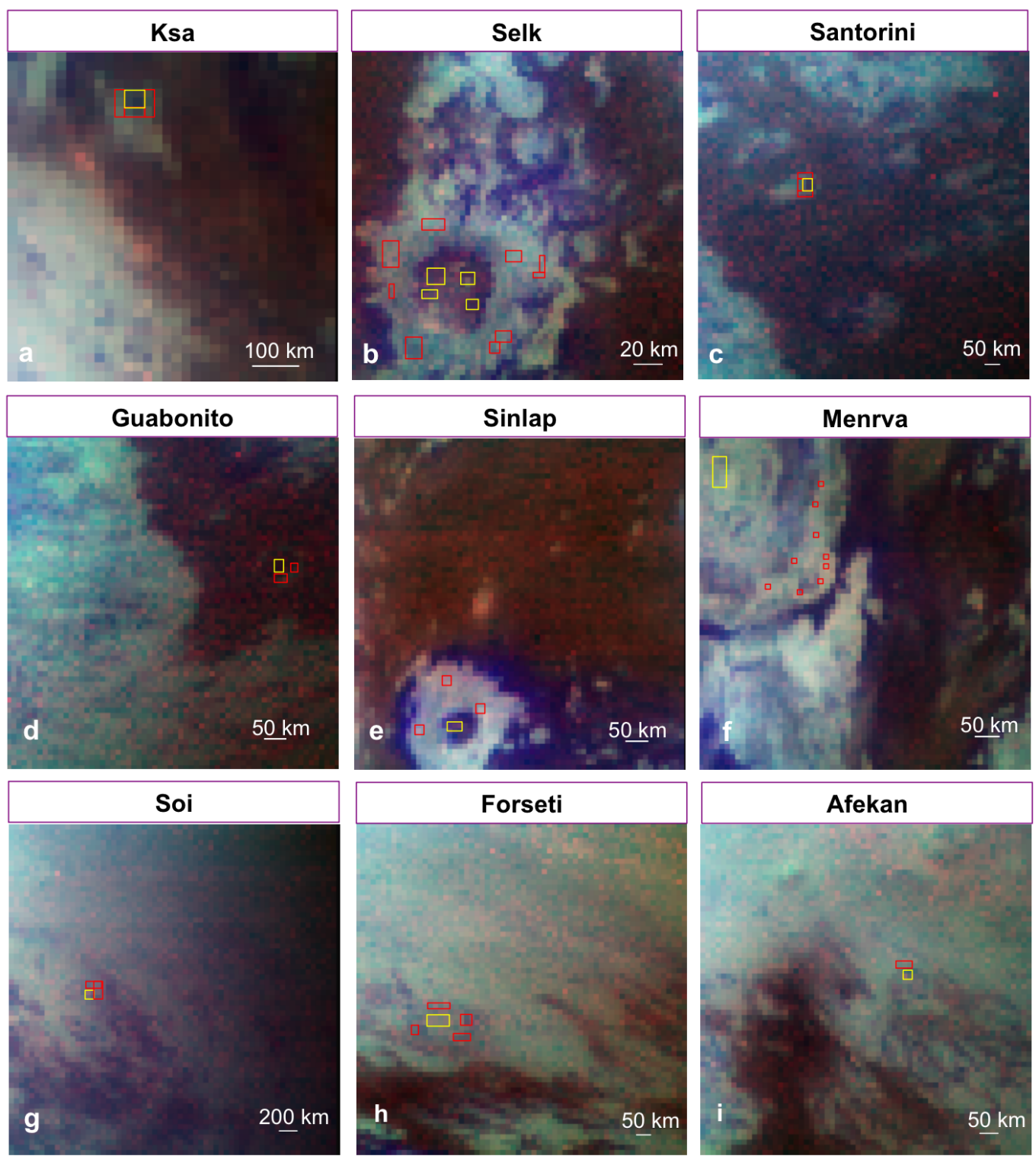

\section{Crater floor (f) \\ Ejecta blanket (e)}

Fig. 2. Detailed view of impact craters studied in this work and associated pixel selections on VIMS datacubes for $(a)$ Ksa, $(b)$ Selk, $(c)$ Santorini, $(d)$ Guabonito, $(e)$ Sinlap, $(f)$ Menrva, $(g)$ Soi, $(h)$ Forseti, and $(i)$ Afekan (R: $5.00 \mu \mathrm{m}, \mathrm{G}: 2.03 \mu \mathrm{m}, \mathrm{B}: 1.27 \mu \mathrm{m})$. Yellow rectangles correspond to the crater floor, red rectangles to the ejecta blanket.

We can estimate the atmospheric contribution to the VIMS data and extract meaningful surface information by using Huygens and Cassini inputs and other parameters, such as laboratory data, that simulate Titan's conditions. Our planeparallel code is based on a Spherical Harmonic Discrete Ordinate Method solver (SHDOMPP; Evans 2007). The inputs include: (a) the vertical profiles of temperature and pressure provided by the Huygens Atmospheric Structure Instrument (HASI; Fulchignoni et al. 2005); (b) the methane vertical mixing ratio from Huygens' Gas Chromatograph Mass Spectrometer (GCMS; Niemann et al. 2010); (c) lines from isotopologs (e.g., ${ }^{12} \mathrm{CH}_{4}$, ${ }^{13} \mathrm{CH}_{4},{ }^{12} \mathrm{CH}_{3} \mathrm{D}, \mathrm{CO}$ ); (d) collision-induced absorption (CIA) coefficients for $\mathrm{N}_{2}-\mathrm{N}_{2}$ and $\mathrm{N}_{2}-\mathrm{H}_{2}$ (McKellar 1989; Lafferty et al. 1996; de Kok et al. 2007); (e) measurements from the Composite Infrared Spectrometer (CIRS) of a uniform CO mole fraction equal to $4.5 \times 10^{5}$ (de Kok et al. 2007); and (f) recent methane absorption coefficients from various sources (e.g., Boudon et al. 2006; Campargue et al. 2012, 2015; Rey et al. 2018) (HITRAN, GEISA).

When the aforementioned components are included, the code produces simulations of the surface albedo with various haze opacities for different locations. The results are calibrated with respect to the albedo derived by the Descent Imager/Spectral Radiometer (DISR) at the Huygens landing site (used as a reference as in our previous papers). By iteration on the best possible fit, the code derives the haze contribution included in the VIMS data. Finally, the code extracts the surface albedos in the windows for the various regions of interest. This result is extracted at full spectral resolution (i.e., surface albedos at all wavelengths contained within the windows) and also in the 


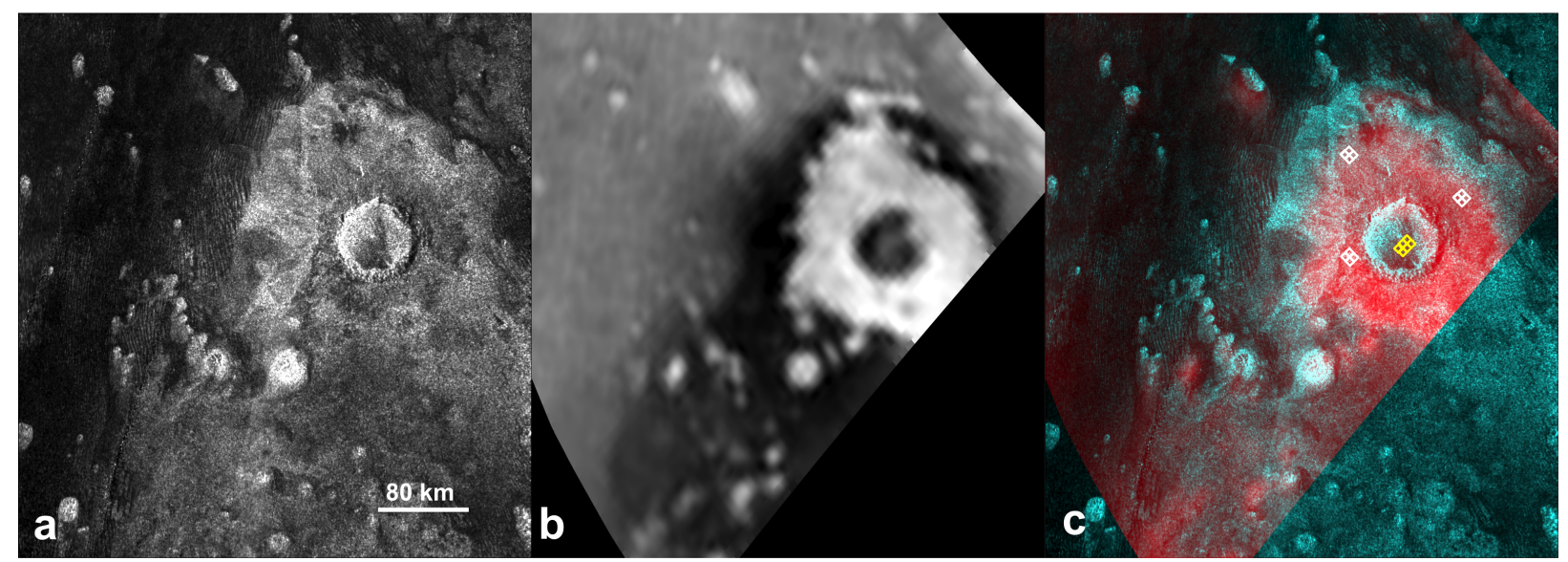

Fig. 3. Example process for identifying regions of interest in the crater floor and ejecta blanket of Sinlap crater: $(a)$ A SAR image of Sinlap from Cassini RADAR; $(b)$ a VIMS image of Sinlap at $2.03 \mu \mathrm{m}$, map projected to match the SAR data; and $(c)$ pixel selection (yellow squares for the crater floor and white squares for the ejecta blanket) using VIMS over SAR (R: $2.03 \mu \mathrm{m}, \mathrm{G}$ : SAR, B: SAR).

form of a weighted average over each window's wavelength range (Fig. 5). The weighted averages correspond to single points of surface albedo within the methane windows with larger weights for channels with higher transmittance around the center (Tomasko et al. 2008; Hirtzig et al. 2013). There are three points between $0.92-0.96 \mu \mathrm{m}, 1.05-1.09 \mu \mathrm{m}$, and $1.27-1.30 \mu \mathrm{m}$; six points between 1.53 and $1.61 \mu \mathrm{m}$; nine points between 1.89 and $2.11 \mu \mathrm{m}$; eight points between 2.68 and $2.80 \mu \mathrm{m}$; and lastly fourteen points between 4.89 and $5.13 \mu \mathrm{m}$. The full width at half maximum (FWHM, i.e., spectral resolution) is $13 \mathrm{~nm}$ below $2.0 \mu \mathrm{m}$, increases up to $22 \mathrm{~nm}$ at $4.2 \mu \mathrm{m}$, and decreases to $18 \mathrm{~nm}$ at $4.8 \mu \mathrm{m}$ (Brown et al. 2004).

The code takes into account a number of uncertainties calculated and summed at the $3 \sigma$ level including the aerosol phase function, the aerosol vertical distribution, the aerosol forced single scattering albedo, the error due to the $\mathrm{CH}_{4}$ vertical concentration profile, the $\mathrm{CH}_{4}$ linelist, and the $\mathrm{CH}_{4}$ far wings profile. In this study, we performed intercomparisons and therefore estimate only relative error bars as indicated in Solomonidou et al. (2016), such as errors in the existing spectral lines profiles, the haze extinction fit, the data intrinsic noise, and the phase function uncertainty. The haze contribution is inverted with an absolute accuracy of $\pm 5 \%$, and the surface albedos with relative errors of $35 \%, 35 \%, 26 \%, 21 \%, 26 \%, 50 \%, 50 \%$, and $43 \%$ for the $0.94,1.08,1.28,1.58,2.03,2.69,2.79$, and $5.00 \mu \mathrm{m}$ windows, respectively. At the very short wavelengths of 0.94 and $1.08 \mu \mathrm{m}$ updated $\mathrm{CH}_{4}$ linelists are not available, thus the error bars are higher compared to $1.28-2.03 \mu \mathrm{m}$, while at the longer wavelengths of $2.69-5 \mu \mathrm{m}$ the uncertainties are larger due to the lower signal to noise ratio $(\mathrm{S} / \mathrm{N})$.

\subsection{Compositional constraints}

We use the extracted surface albedos (shown in Sect. 4, Fig. 5) to examine the compositional properties of the craters in our study. We specifically looked for differences between the crater floors and ejecta blankets, as well as differences based on geographic location and degradation state. In order to constrain the composition of the craters using VIMS data, we tested their spectral properties against a spectral library of various constituents: water ice $\left(\mathrm{H}_{2} \mathrm{O}\right)$ at 15 grain sizes $(10,20,30,40,50,75,100,150$, 200, 250, 300, 400, 500, 750, and $1,000 \mu \mathrm{m})$, laboratory tholins produced at 6 different grain sizes $(1,2,5,10,30$, and $100 \mu \mathrm{m})$ and dark materials such as bitumens (kerite, asphaltite, different types of anthraxolite), and amorphous carbon $(\mathrm{aC})$ at three different grain sizes $(10,200$, and $500 \mu \mathrm{m})$ (Fig. 4). These dark materials have been suggested to be similar to materials capable of lowering the total surface albedo in many regions on Titan (Lellouch 2006). In addition, we have included in our model simulations carbon dioxide ice $\left(\mathrm{CO}_{2}\right)$, ammonia ice $\left(\mathrm{NH}_{3}\right)$ and a methane-like ice, also at 15 grain sizes. Due to the massive atmospheric thermal inertia, methane ice will not be stable on the surface of Titan, therefore the spectra we use for the $\mathrm{CH}_{4}$-like ice represent the solid form of an organic molecule containing methyl $\left(\mathrm{CH}_{3}\right)$, methylene $\left(\mathrm{CH}_{2}\right)$, or methinyl $(\mathrm{CH} \mathrm{C}-\mathrm{H})$ bonds. Hereafter we refer to this component as $\mathrm{CH}_{4}$-like ice.

As in our previous studies (Solomonidou et al. 2014, 2018) all spectra, (including the hydrocarbon $\mathrm{CH}_{4}$-like, $\mathrm{CO}_{2}$, and $\mathrm{NH}_{3}$ spectra that are used for the first time in this study) were obtained from the GhoSST database ${ }^{2}$ (including work by Bernard et al. 2006; Lellouch 2006; Brassé et al. 2015). Taking into account the different grain sizes and different types of dark material considered, in total we looked at 75 different spectra. We used a method that extracts the major constituents in the regions of interest and is fully described in Solomonidou et al. (2014, 2018).

\section{Results and interpretations}

We present an example of the results produced by the RT code in Fig. 5, which is a comparison between two typical units on Titan (Table 1), adapted from previously analyzed VIMS data in Solomonidou et al. (2016, 2018) and Lopes et al. (2016). This comparison is used in order to show the differences in albedo between the two major units studied in this work.

Figure 5 also illustrates the differences in haze contribution included in the data of these units. The dunes are very close to the DISR measurements of the haze above the Huygens landing site (HLS) $(98 \%)$. The plains have about $17 \%$ more haze than the HLS. The $19 \%$ difference between the dunes and the plains is attributable to the differences in location and year of data acquisition. There is also a notable difference in the surface albedo between the dunes and the undifferentiated plains of the midlatitudes, the two areas on Titan where we apply the RT code. The surface terrains with craters that we examined in this work have the following characteristics: the dunes are particularly dark

\footnotetext{
http://ghosst.osug. fr
} 

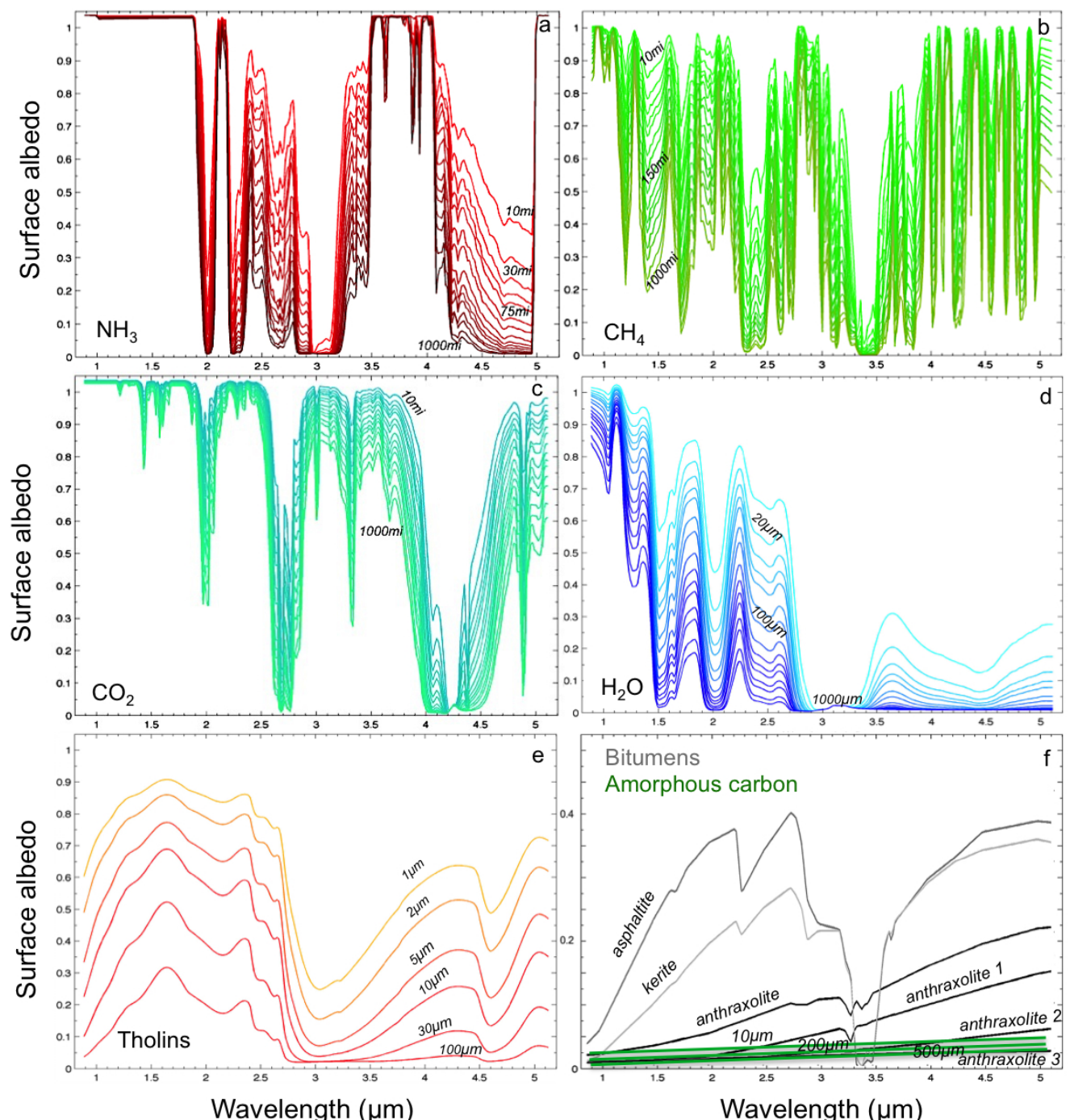

Fig. 4. Candidate components of Titan's surface examined in this work: $(a) \mathrm{NH}_{3}$ in shades of red; $(b) \mathrm{CH}_{4}$-like organic in shades of light green; (c) $\mathrm{CO}_{2}$ in shades of turquoise; $(d) \mathrm{H}_{2} \mathrm{O}$ in shades of blue; $(e)$ laboratory tholins in yellow-orange; $(f)$ bitumens in gray, and amorphous carbon in shades of green. These spectra are plotted in the spectral range of VIMS at different grain sizes (Bernard et al. 2006; Brassé et al. 2015; GhoSST database, http://ghosst. osug.fr).

with low surface albedo values and an almost flat shape in their spectral response, while the undifferentiated plains of the northern midlatitudes are significantly brighter in albedo. As shown in Solomonidou et al. (2018), they are one of the brightest units on Titan.

We use the aforementioned albedos from the dunes and the undifferentiated plains for context purposes, as we did in Solomonidou et al. (2014, 2016, 2018, 2020). In those works, we analyzed VIMS data with RT that included all major Titan surface units and observations from different flybys, acquired at different times. The results showed the variability in spectral response from Titan's surface, indicative of diverse chemical compositions and origins. Furthermore, the results showed the adequacy of comparing extracted albedos with RT from different datacubes with different observational geometries and different spatial resolution. These are properties that the RT code takes into account when estimating the haze contribution and extracting the surface albedo from the VIMS data.

Focusing now on the analyses of the craters, we have extracted the percentages of the haze contributions to the data, ratioed to Huygens' DISR measurements and the surface albedos. The results are shown in Fig. 6 along with the surface albedo retrievals. We find that the haze contributions are about 100$120 \%$ with respect to DISR (consistent with what is expected at these latitudes). We find that the haze contributions in the craters can be significantly different even when comparing units located close to one another geographically (for instance between Ksa and Santorini, two equatorial dune craters, we have up to $19 \%$ of haze difference and even nearby craters like Afekan and Selk have up to $11 \%$ haze difference). This demonstrates the necessity for atmospheric treatment of the VIMS data even within the methane windows where the atmospheric contributions are relatively low with respect to the wings of the methane band.

In Fig. 6, two albedo groups are significantly distinct for the crater floors: one for the plain craters with higher albedo values at all wavelengths and one for the dune craters, which are darker than the plain craters at all wavelengths. For the ejecta blankets, the same distinction is obvious at $1.27,1.59$, and $2.03 \mu \mathrm{m}$ and could also apply to the double window at 2.69 and $2.79 \mu \mathrm{m}$ and at $5.00 \mu \mathrm{m}$, but we cannot confirm that given the uncertainties. 


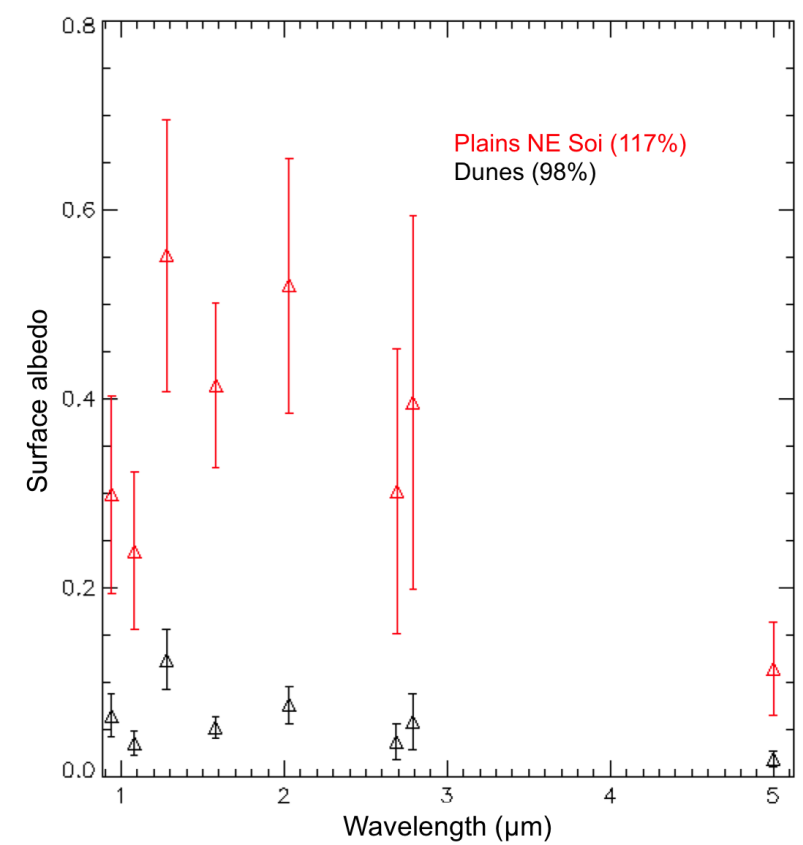

Fig. 5. Weighted surface albedo of the undifferentiated plains NE of Soi crater $\left(133^{\circ} \mathrm{W}, 30^{\circ} \mathrm{N}\right)$ (red triangles) and the dunes of the Belet sand sea $\left(237^{\circ} \mathrm{W}, 5^{\circ} \mathrm{N}\right)$ (black triangles). This figure shows results from the data analysis presented in Solomonidou et al. $(2016,2018)$ and Lopes et al. (2016), provided as context for the present work. The percentages next to the names in the labels correspond to the haze contributions to the data with respect to Huygens' Descent Imager/Spectral Radiometer (DISR) measurements.

In Figs. 7a and b, we show an in-depth example of one plain and one dune crater (Afekan and Selk) from Fig. 6. In addition, we show the special cases of Menrva and Sinlap. The surface albedos for Menrva and Sinlap (Figs. $7 \mathrm{c}$ and d), are significantly different in values and spectral responses from those of the dune and plain crater groups, and thus both craters are treated as "special cases". This is consistent with past studies that show the unique nature of both craters (e.g., Le Mouélic et al. 2008; Neish et al. 2013; Crosta et al. 2019). Menrva is by far the largest impact crater on Titan. It has a diameter of $\sim 425 \mathrm{~km}$, roughly three times larger than the next largest crater, Forseti, with a diameter of $\sim 140 \mathrm{~km}$ (Hedgepeth et al. 2020). Due to its size, Menrva also straddles the equatorial dunes and the midlatitude plains on Titan, making it difficult to categorize geographically. Sinlap is very likely the youngest and/or best-preserved impact crater on Titan (Le Mouélic et al. 2008; Neish et al. 2015, 2016; Werynski et al. 2019).

In Fig. 7, we show the results for the retrieval of the major constituents for the ejecta blankets and the crater floors of Afekan, Selk, Menrva, and Sinlap. We use linear mixtures of $\mathrm{H}_{2} \mathrm{O}, \mathrm{CH}_{4}$-like organic, $\mathrm{CO}_{2}$, and $\mathrm{NH}_{3}$ ices, dark material, and tholin components. The simulations provide the best possible fit for all the windows simultaneously, minimizing the residuals. As expected, and already discussed in Solomonidou et al. (2018), the fits between the simulated materials and the surface albedos are not perfect, but they provide very good insight into Titan's surface composition. Indeed, in Solomonidou et al. (2018), we evaluated to what extent the available observations can be classified spectrally in terms of mixtures rich in a specific major component. In that work, we found that it was particularly difficult to reproduce the $0.94,1.08$, and $2.03 \mu \mathrm{m}$ albedo values. In this present study, however, we have added more components in our simulations, increasing the number of spectroscopic data available for possible matches in our library from 30 to 75, when taking into account the grain sizes. As discussed in Solomonidou et al. (2018), the library of components corresponding to "tholin-like" materials may differ from the aerosols produced in Titan's atmosphere and then processed at the surface by fluvial/pluvial/aeolian activity, since they are produced in the laboratory. In addition, when the code extracts the abundance of water ice from a region, it is consistent with any $\mathrm{OH}$-bearing constituents, not uniquely $\mathrm{H}_{2} \mathrm{O}$. Hence, we have now obtained good matches for five out of the eight wavelengths in all craters: $0.94,1.08,1.59,2.69$, and $5 \mu \mathrm{m}$ (for the last wavelength, the only exception is Sinlap crater). As discussed in Sect. 3.2, the matches for the double window $(2.69$ and $2.79 \mu \mathrm{m})$, the very short wavelengths, and the very long wavelengths are more difficult to achieve. We also have a good match at $1.28 \mu \mathrm{m}$ in all regions except for Selk crater, the Afekan floor, and the Menrva ejecta. There is no match (or there is a very marginal match) at 2.03 and $2.79 \mu \mathrm{m}$ at all regions except for Sinlap crater where we have a good fit. The $\chi^{2}$ values for all eight areas are low, ranging from 0.15 to 1.68 , which means that there is a high correlation between the albedo data and the composition simulations.

Titan's surface is likely to be far more complex than a mixture of six materials, and we acknowledge that this is a simplistic assumption. However, it is important to test the limits that we can reach given the type of data provided by Cassini and the current knowledge of Titan's surface composition. With all these caveats in mind, we use these data to infer the constraints on the composition of the units we examined.

By analyzing Figs. 6 and 7, it is obvious that regardless of what material was exposed through the cratering process, both dune and plain craters have been altered compositionally, with different results depending on the geographic region in which they are located. The plain craters of Soi, Forseti, and Afekan seem to have significantly higher albedos compared to the dune craters of Ksa, Selk, Guabonito, and Santorini for both the crater floors and ejecta blankets (especially at shorter wavelengths: $1.27,1.59$, and $2.03 \mu \mathrm{m}$ ). The difference at these specific wavelengths is similar to the differences in albedo observed for typical undifferentiated plains and dunes regions (Fig. 5).

In an effort to make this crater compositional study as thorough as possible, we then added the emissivity information for all nine craters as provided by Werynski et al. (2019) from RADAR radiometry data (Table 2). We also included relative age estimates where available from Neish et al. (2018) (Table 2). These are based on the relative depths of the craters as compared to undegraded craters of similar size on Ganymede; shallower craters are assumed to be more infilled and thus older Neish et al. (2013, 2018); Hedgepeth et al. (2020). It is important to note that microwave emissivity measurements probe greater depths (tens of centimeters) than VIMS measurements (tens of microns). Thus, emissivity represents the subsurface compositional nature of an area, while the VIMS data captures the very thin layer that covers the surface. Lower emissivity values are related to strong volume subsurface scattering and suggest that regions are enriched in icy material, while higher emissivity values correspond to more organic-rich regions. Hence, when the RADAR emissivity values interpretation agrees with the VIMS compositional analysis, it provides a glimpse at the overall compositional nature of the crater deposits in the top decimeter of the regolith. If emissivity and VIMS compositional interpretations differ, then erosion and weathering have likely altered the superficial layer of the crater and/or caused infilling of the subsurface by organic materials. 

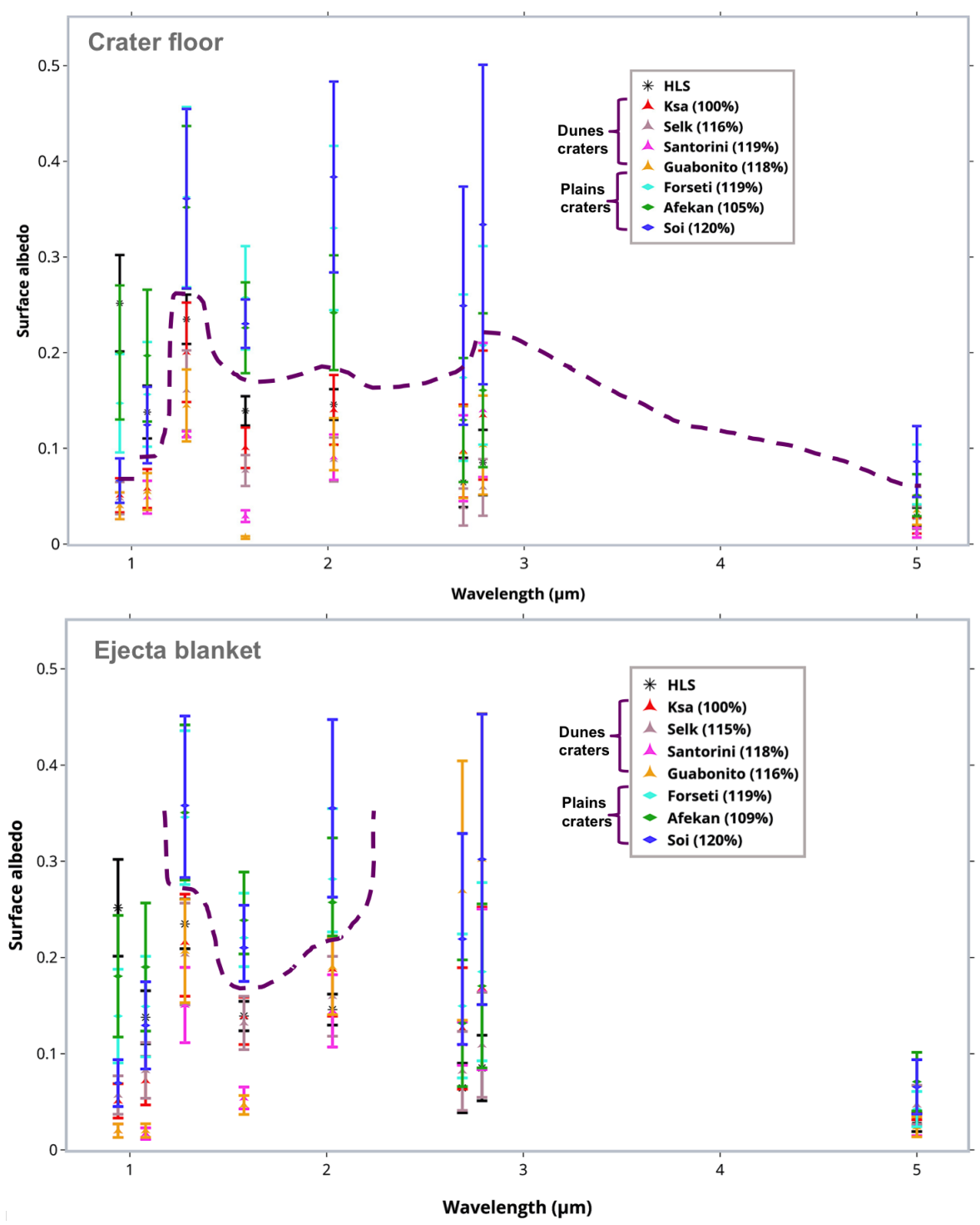

Fig. 6. Weighted surface albedos (symbols) in the methane windows extracted from VIMS using radiative transfer analysis for crater floors (upper) and the ejecta blankets (lower) of the dune and plain impact craters. The percentages next to the names in the labels correspond to the haze contributions to the data with respect to Huygens' DISR measurements. The dashed magenta lines are drawn to show the distinction between the spectral responses between the dunes and the plain craters at specific wavelengths. Note that Sinlap and Menrva are not included in this figure, but are treated as special cases later in the manuscript. HLS stands for Huygens Landing Site.
Figure 8 shows that the dune crater floors and the dune ejecta blankets are separated compositionally from the plain crater floors and plain crater ejecta in a ternary diagram. Special case Menrva presents the same composition for the crater floor and the ejecta blanket, appearing most similar to a degraded plain crater (Soi). From our compositional analysis, we find that the dune crater floors are rich in the dark unknown material $(\sim 70-$ $-90 \%)$, followed by the tholin-like constituent ( $\sim 10-30 \%)$, with an absence of any ice constituent. The ejecta blankets have less dark material (up to $\sim 55-65 \%$ abundance) and more tholinlike material (up to $\sim 35-45 \%$ abundance) than the crater floors, which explains their brighter appearance in the infrared. Again, ices are absent at the surface of all ejecta blankets in the dunes region (apart from Sinlap, which we discuss below). In contrast, the crater floors in the plains consist mainly of tholin-like material $(\sim 55-80 \%)$, dark components $(\sim 0-25 \%)$, and water ice $(\sim 15-20 \%)$. In contrast to the dune craters, where the ejecta blanket composition is significantly different from the crater floor composition, there is little difference in the composition of the floors and the ejecta blankets of the plain craters. The plain crater ejecta blankets consist mainly of tholin-like material $(\sim 45-85 \%)$, dark material $(\sim 0-40 \%)$, and water ice $(\sim 10-30 \%)$. Hence, the plain craters consist of a mixture of ice (water ice and a small amount of methane ice) and organic material, while the dune craters are consistent with a purely organic nature (the unknown dark material is expected to be organic (e.g., Solomonidou et al. 2018). In addition to tholins, the dark organic material, and $\mathrm{H}_{2} \mathrm{O}$, ice we have tested other ices in different grain sizes such as $\mathrm{CH}_{4}$-like, $\mathrm{CO}_{2}$, and $\mathrm{NH}_{3}$. We find that adding other organic molecules such as those containing $\mathrm{CH}_{3}, \mathrm{CH}_{2}$, and $\mathrm{CH} \mathrm{C}-\mathrm{H}$ bonds significantly improves the fit of the ejecta of Sinlap and Afekan at all short wavelengths $(0.94-2.03 \mu \mathrm{m})$, whereas adding $\mathrm{CO}_{2}$ and $\mathrm{NH}_{3}$ in the mixtures does not offer any improvement in the fits. Hence, the 'total organic' percentages that correspond to the expected presence of organics (tholins, unknown dark organic material, and $\mathrm{CH}_{4}$-like) in the mixture is $100 \%$ for the dune craters, and ranges between 70 and $88 \%$ for the plains and special case craters.

Interestingly, the dark material is absent from the mixtures of Soi in both units. This is something that was also observed in Menrva, which we treat as a special case due to its size and geographic location, in addition to being the crater with the brightest albedo. For Menrva, the ejecta blanket and the crater floor seem to consist of the same mixture in similar abundances, since Menvra is enormously large in size $(425 \pm 25 \mathrm{~km})$ and seems to straddle the dunes and the plains. It is important to note here 


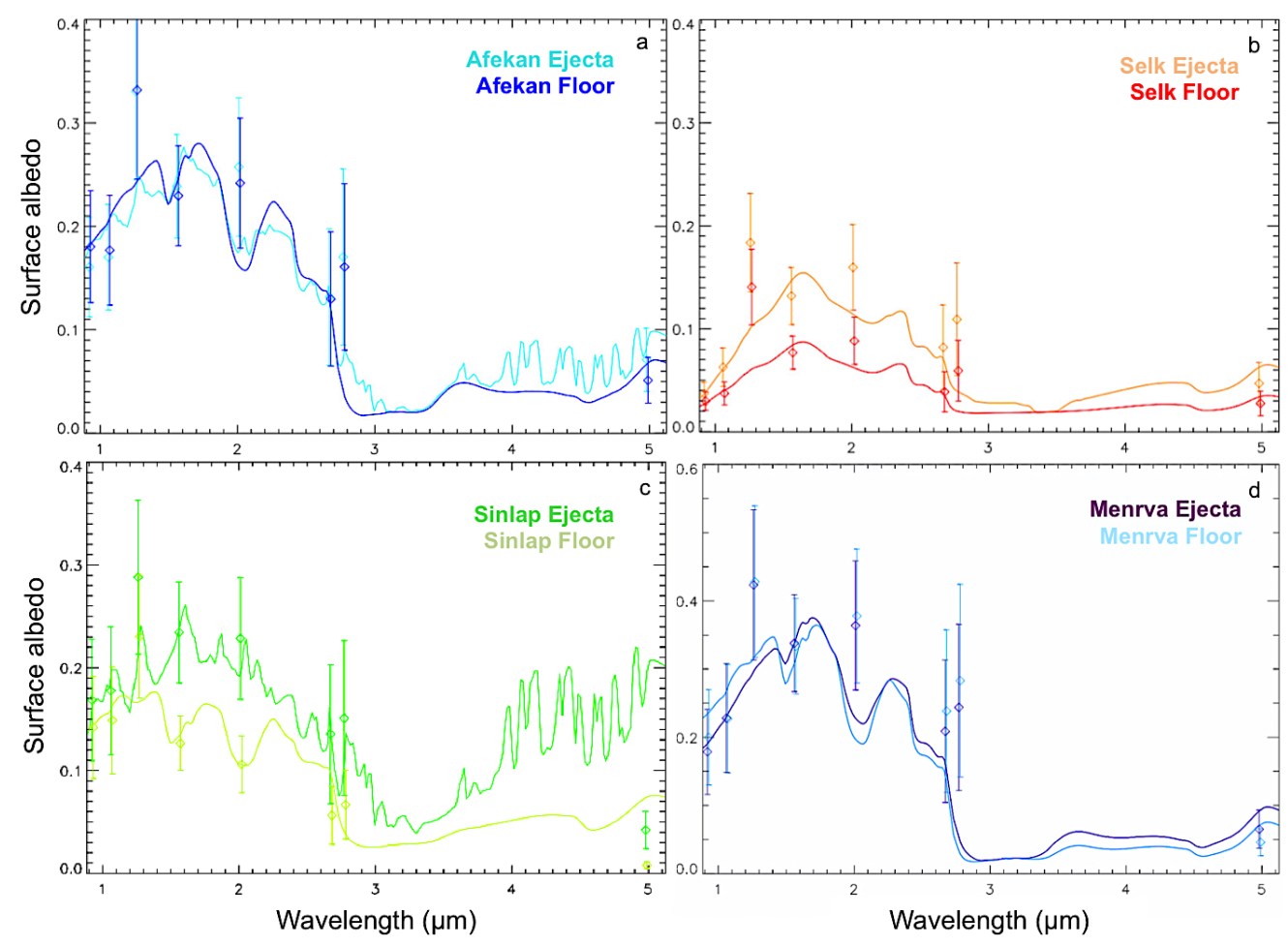

Fig. 7. Inferred compositional constraints for four different craters (as an example) and their subunits. The diamond symbols correspond to the extracted surface albedos as shown in Fig. 6, and the full lines to the compositional simulations, which are produced by the code using the best fit attained between the laboratory spectra and the albedos. Panel a shows the surface albedo results of one typical plains crater (Afekan -in turquoise for the ejecta blanket and blue for the crater floor); panel $b$ shows the results for one typical dunes crater (Selk -in orange for the ejecta blanket and red for the crater floor); panels $c$ and $d$ show the results from the two special cases (Sinlap - in green for the ejecta blanket and light green for the crater floor, and Menrva - in magenta for the ejecta blanket and light blue for the crater floor). From $(a)$ and $(b)$ we infer that Afekan is enriched in water ice and Selk has an organic-rich nature with no obvious water ice. Panels $c$ and $d$ (we note the change in scale) present two craters that differ from the rest on Titan. Both Sinlap and Menrva have strong signatures of water ice in their mixtures. The $3 \sigma$ error bars are inferred by the code during the extraction of the surface albedos. The $\chi^{2}$ values for all eight areas range from 0.15 to 1.68 , which means that there is a high correlation between the albedo data and the composition simulations.

that the units of "crater floor" and "ejecta blanket" are less meaningful for a crater of this size, since extremely large craters have different morphologies than a typical complex crater. The other special case crater is Sinlap, which may be the best-preserved crater on Titan (Neish et al. 2018). Even though Sinlap is located in the equatorial dunes, we were unable to classify it in one of the two groups, possibly because of its very young age. In both the ejecta blanket and the crater floor, areas of water ice are present at $\sim 15-20 \%$ abundance. The crater floor of Sinlap seems more consistent with the dune craters group, while the ejecta, which seems to be enriched in ice containing organic molecules with features similar to methane ice $(10 \%)$ pairs better with the plain craters (Table 2). We note that evidence of dune materials are obvious in high-resolution VIMS RGB images of Sinlap (Neish et al. 2015), supporting the idea that there is more dune material on the floor of Sinlap than in its continuous ejecta blanket (although the ejecta unit defined here is surrounded to the north, west, and south by sand dunes).

\section{Discussion and implications}

\subsection{Impact crater evolution on Titan}

In this work, we obtained compositional data from Titan's impact craters, derived from their extracted albedos, and compared them with the microwave emissivity values obtained by Werynski et al. (2019). Now, we compare our results to the scenario of impact crater evolution proposed by Werynski et al. (2019).

Werynski et al. (2019), suggest that the dunes regions that host craters are covered by a thick layer of sand (10s of meters; Neish et al. 2010) over a water ice substrate. After impact, the water ice and sand are intimately mixed in the ejecta blanket, with low emissivity values resulting from fractures in the water ice. Following this, the substrate fractures are filled in with organic material and the emissivity increases accordingly. For the plains regions that host craters, Werynski et al. (2019) suggest a similar scenario. However, in this case the top organic layer is thinner and thus the resulting mixture is enriched in water ice, making water ice more obvious in the spectral responses. Based on emissivity data, the study suggest that well-preserved craters have a subsurface enriched with water ice compared to older (more degraded) craters. The differences in the VIMS data were attributed by Werynski et al. (2019) to active exogenic processes that clear off the surficial layers, making the equatorial dune craters appear more enriched in organic material (due to the mixture of ice and organics that occurred during impact), while the midlatitude plain craters appear more water ice rich.

Our study agrees in many aspects with the scenario presented in Werynski et al. (2019). For example, the plain craters appear to be more enriched in water ice compared to the dune craters, suggesting either a thinner organic covering there, or less exogenic (aeolian in particular) activity. However, there is no evidence 
A. Solomonidou et al.: The chemical composition of impact craters on Titan. I.

Table 2. Compositional constraints for the crater floors (f) and ejecta blankets (e) of the dune and plain craters given by percentages of the six main constituents $\left(\mathrm{H}_{2} \mathrm{O}, \mathrm{NH}_{3}, \mathrm{CO}_{2}, \mathrm{CH}_{4}\right.$-like, tholin-like, and dark material).

\begin{tabular}{|c|c|c|c|c|c|c|c|c|}
\hline \multirow{2}{*}{$\begin{array}{c}\text { Dune craters } \\
\text { Unit }\end{array}$} & \multicolumn{2}{|c|}{ Ksa } & \multicolumn{2}{|c|}{ Selk } & \multicolumn{2}{|c|}{ Santorini } & \multicolumn{2}{|c|}{ Guabonito } \\
\hline & $\mathrm{f}$ & $\mathrm{e}$ & $\mathrm{f}$ & $\mathrm{e}$ & $\mathrm{f}$ & $\mathrm{e}$ & $\mathrm{f}$ & $\mathrm{e}$ \\
\hline Tholin & $\begin{array}{c}16 \% \\
( \pm 4 \%)\end{array}$ & $\begin{array}{c}47 \% \\
( \pm 13 \%)\end{array}$ & $\begin{array}{c}21 \% \\
( \pm 6 \%)\end{array}$ & $\begin{array}{c}36 \% \\
( \pm 13 \%)\end{array}$ & $\begin{array}{c}30 \% \\
( \pm 5 \%)\end{array}$ & $\begin{array}{c}42 \% \\
( \pm 11 \%)\end{array}$ & $\begin{array}{c}13 \% \\
( \pm 3 \%)\end{array}$ & $\begin{array}{c}40 \% \\
( \pm 11 \%)\end{array}$ \\
\hline Dark material & $\begin{array}{c}84 \% \\
( \pm 7 \%)\end{array}$ & $\begin{array}{c}53 \% \\
( \pm 15 \%)\end{array}$ & $\begin{array}{c}79 \% \\
( \pm 8 \%)\end{array}$ & $\begin{array}{c}64 \% \\
( \pm 15 \%)\end{array}$ & $\begin{array}{c}70 \% \\
( \pm 8 \%)\end{array}$ & $\begin{array}{c}58 \% \\
( \pm 13 \%)\end{array}$ & $\begin{array}{c}87 \% \\
( \pm 10 \%)\end{array}$ & $\begin{array}{c}60 \% \\
( \pm 15 \%)\end{array}$ \\
\hline $\mathrm{H}_{2} \mathrm{O}$ & - & - & - & - & - & - & - & - \\
\hline $\mathrm{CH}_{4}$-like & - & - & - & - & - & - & - & - \\
\hline $\mathrm{NH}_{3}$ & - & - & - & - & - & - & - & - \\
\hline $\mathrm{CO}_{2}$ & - & - & - & - & - & - & - & - \\
\hline Emissivity & 0.92 & 0.93 & 0.93 & 0.85 & 1 & 0.95 & 0.98 & 0.95 \\
\hline Degradation state & \multicolumn{2}{|c|}{ well-preserved } & \multicolumn{2}{|c|}{ intermediate } & \multicolumn{2}{|c|}{ degraded } & \multicolumn{2}{|c|}{ degraded } \\
\hline Plain craters & \multicolumn{2}{|c|}{ Forseti } & \multicolumn{2}{|c|}{ Afekan } & \multicolumn{2}{|c|}{ Soi } & & \\
\hline Unit & $\mathrm{f}$ & $\mathrm{e}$ & $\mathrm{f}$ & $\mathrm{e}$ & $\mathrm{f}$ & $\mathrm{e}$ & & \\
\hline Tholin & $\begin{array}{c}53 \% \\
( \pm 17 \%)\end{array}$ & $\begin{array}{c}46 \% \\
( \pm 15 \%)\end{array}$ & $\begin{array}{c}54 \% \\
( \pm 15 \%)\end{array}$ & $\begin{array}{c}50 \% \\
( \pm 13 \%)\end{array}$ & $\begin{array}{c}80 \% \\
( \pm 16 \%)\end{array}$ & $\begin{array}{c}82 \% \\
( \pm 15 \%)\end{array}$ & & \\
\hline Dark material & $\begin{array}{c}27 \% \\
( \pm 8 \%)\end{array}$ & $\begin{array}{c}24 \% \\
( \pm 7 \%)\end{array}$ & $\begin{array}{c}31 \% \\
( \pm 7 \%)\end{array}$ & $\begin{array}{c}30 \% \\
( \pm 10 \%)\end{array}$ & - & - & & \\
\hline $\mathrm{H}_{2} \mathrm{O}$ & $\begin{array}{c}20 \% \\
( \pm 5 \%)\end{array}$ & $\begin{array}{c}30 \% \\
( \pm 5 \%)\end{array}$ & $\begin{array}{c}15 \% \\
( \pm 3 \%)\end{array}$ & $\begin{array}{c}12 \% \\
( \pm 3 \%)\end{array}$ & $\begin{array}{c}20 \% \\
( \pm 5 \%)\end{array}$ & $\begin{array}{c}18 \% \\
( \pm 5 \%)\end{array}$ & & \\
\hline $\mathrm{CH}_{4}$-like & - & - & - & $\begin{array}{c}8 \% \\
( \pm 2 \%)\end{array}$ & - & - & & \\
\hline $\mathrm{NH}_{3}$ & - & - & - & - & - & - & & \\
\hline $\mathrm{CO}_{2}$ & - & - & - & - & - & - & & \\
\hline Emissivity & 0.93 & 0.83 & 0.95 & 0.93 & 0.93 & 0.90 & & \\
\hline Degradation state & \multicolumn{2}{|c|}{ intermediate } & \multicolumn{2}{|c|}{ intermediate } & \multicolumn{2}{|c|}{ degraded } & & \\
\hline Special cases & \multicolumn{2}{|c|}{ Menrva } & \multicolumn{2}{|c|}{ Sinlap } & & & & \\
\hline Unit & $\mathrm{f}$ & e & $\mathrm{f}$ & $\mathrm{e}$ & & & & \\
\hline Tholin & $\begin{array}{c}82 \% \\
( \pm 19 \%)\end{array}$ & $\begin{array}{c}83 \% \\
( \pm 18 \%)\end{array}$ & $\begin{array}{c}15 \% \\
( \pm 4 \%)\end{array}$ & $\begin{array}{c}22 \% \\
( \pm 5 \%)\end{array}$ & & & & \\
\hline Dark material & - & - & $\begin{array}{c}65 \% \\
( \pm 6 \%)\end{array}$ & $\begin{array}{c}53 \% \\
( \pm 13 \%)\end{array}$ & & & & \\
\hline $\mathrm{H}_{2} \mathrm{O}$ & $\begin{array}{c}18 \% \\
( \pm 5 \%)\end{array}$ & $\begin{array}{c}17 \% \\
( \pm 4 \%)\end{array}$ & $\begin{array}{c}20 \% \\
( \pm 5 \%)\end{array}$ & $\begin{array}{c}15 \% \\
( \pm 5 \%)\end{array}$ & & & & \\
\hline $\mathrm{CH}_{4}$-like & - & - & - & $\begin{array}{c}10 \% \\
( \pm 3 \%)\end{array}$ & & & & \\
\hline $\mathrm{NH}_{3}$ & - & - & - & - & & & & \\
\hline $\mathrm{CO}_{2}$ & - & - & - & - & & & & \\
\hline Emissivity & 0.90 & 0.87 & 0.84 & 0.85 & & & & \\
\hline Degradation state & \multicolumn{2}{|c|}{ well-preserved } & \multicolumn{2}{|c|}{ well-preserved } & & & & \\
\hline
\end{tabular}

Notes. The associated error under each percentage corresponds to the uncertainty of the abundances of the component within the mixtures. The microwave emissivity measurements from the Cassini RADAR radiometry data set are provided in Werynski et al. (2019) and shown in Fig. 1c. As in Werynski et al. (2019), we interpret the low emissivity values $(<0.90)$ to be consistent with an enrichment in water ice and the high emissivity values $(>0.95)$ with an enrichment in organic materials in the top decimeter of the regolith. The relative degradation state is taken from information in Neish et al. $(2013,2018)$, and Werynski et al. (2019). 


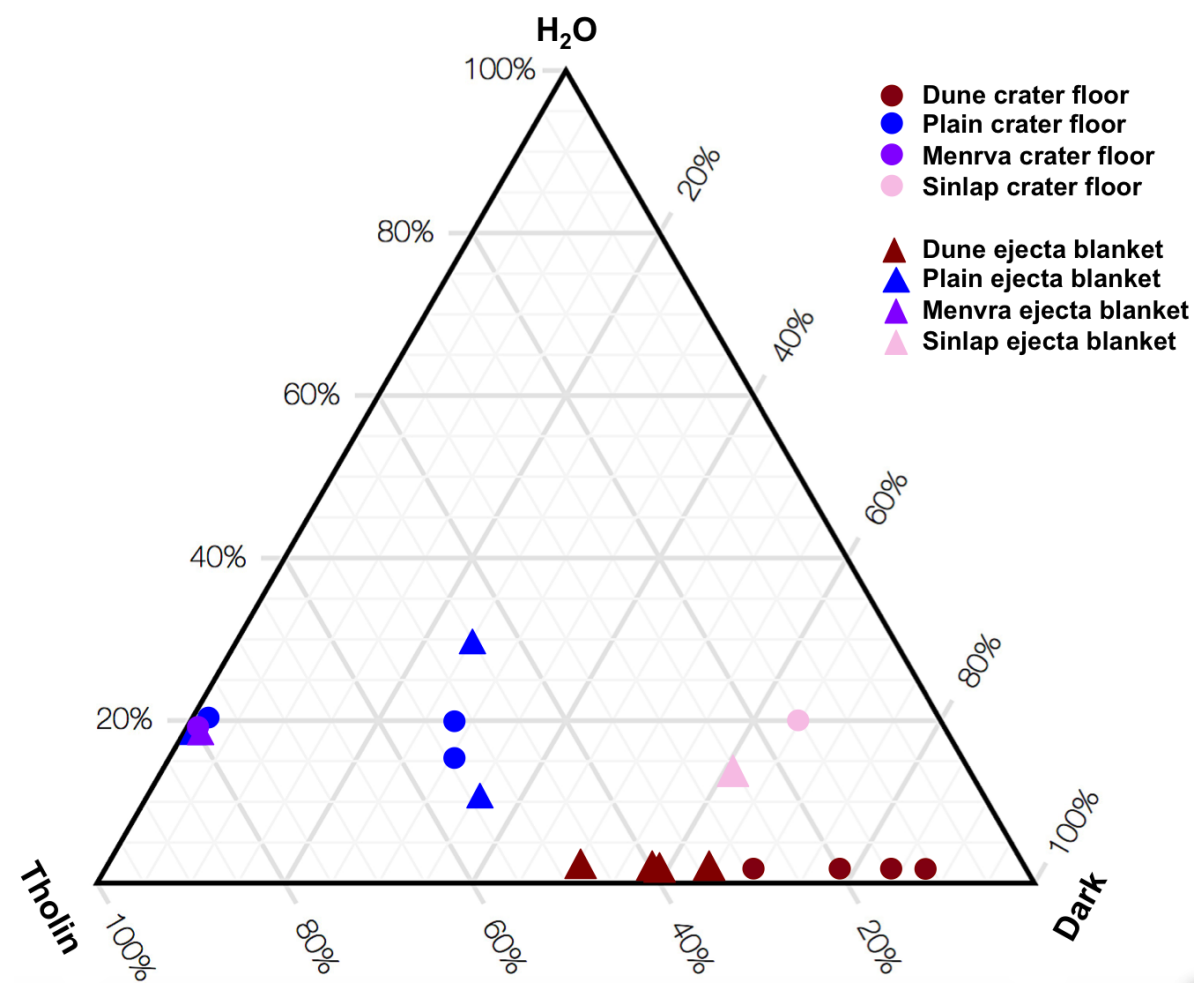

Fig. 8. Ternary diagram with each of the three apexes representing a composition from the three major constituents: OH-bearing constituent (e.g., $\mathrm{H}_{2} \mathrm{O}$ ), tholin-like constituent, and unknown dark constituent. The circles represent the crater floors and the triangles the ejecta blankets. The brownish-red color corresponds to the dune craters, the blue to the plain craters, the magenta to Menrva, and the pink to Sinlap. We note the close overlap between the symbols for the composition of Soi and Menrva subunits. for the presence of water ice in the dune craters, as was predicted by Werynski et al. (2019), except in the case of Sinlap. Our interpretation suggests that the original composition of the crater was a mix of organics and water ice, but there is a very fast exogenic process covering the dune craters with organic material, not clearing the top surface as suggested in Werynski et al. (2019).

Thus, we have shown that the use of an RT code that estimates the atmospheric contribution to the VIMS data for the different craters, and the use of the library of candidate Titan components in the VIMS wavelength range, provides more information about the spectral nature of the crater floors and ejecta blankets of Titan's impact craters than simple RGB composites alone. The results are based on a fusion of information that includes the estimated abundances of the major constituents in the surface material mixtures of the craters (both crater floor and ejecta blanket), their spectral responses and albedo values, their emissivity values, and the relative degradation states of the craters.

\subsection{The special cases of Menrva and Sinlap}

The special cases of Menvra and Sinlap have retrieved albedos that differ markedly from the albedos retrieved from the dune and plain craters. Specifically, for Menrva the 1.27 and $1.59 \mu \mathrm{m}$ albedo is significantly higher than any other crater for both the floor and the ejecta blanket. The same applies for Sinlap, but only for the ejecta blanket, which also appears to be enriched in $\mathrm{CH}_{4}$ like ice. This suggests that the mixture of materials that covers these two craters is different than the mixture covering the others, in nature or in grain size. The water ice abundance for the two craters is roughly the same, although the dark material and tholin components differ significantly. Menrva has no detectable dark material in either the crater floor or ejecta blanket, similar to the (relatively degraded) plains crater Soi. Sinlap has a significant amount of dark material in its crater floor and ejecta blanket. This difference may be the result of the location of the two craters. Sinlap is located within the dune field of Fensal and the interaction of dune material with the crater is likely to heavily influence its composition. Menrva, located on the boundary of the plains and the dunes, appears spectrally most like a degraded plains crater. However, its emissivity is similar to that of Sinlap, suggesting that both craters are a mixture of organics and water ice.

The presence of water ice in Sinlap's floor and ejecta blanket suggests that the top layer of this structure has not been long exposed, supporting previous work that suggests a youthful age. No other crater in the dunes fields has any recognizable water ice signature in its spectra, even Ksa, which morphologically appears to be quite fresh (Neish et al. 2013). It is possible that the small size of Ksa $(40 \mathrm{~km}$ diameter vs. $80 \mathrm{~km}$ diameter of Sinlap) is responsible for its complete coverage by organic dune material and the complete absence of the water ice component, despite its youthful age. Smaller craters expose materials from shallower regions in the crust, and will be more quickly covered by exogenic deposits. Still, Sinlap seems to represent how a very young -if not the youngest- impact crater within a dune sea might look.

\subsection{The dune craters}

The other dune craters present more degraded examples of impact craters in Titan's sand seas. Both Santorini and Guabonito have no recognizable water ice in the top layer, and are covered entirely by tholin and dark material. This is consistent with the emissivity values $(0.95-1)$, which indicate an organic composition in the near subsurface as well (Janssen et al. 2016; Werynski et al. 2019). Both craters appear morphologically degraded, and are shallower than most of the other craters, which fits well with their apparent organic-rich nature. The final dunes crater in this study is Selk, which in terms of spectral response seems similar to Santorini and Guabonito, though it presents large differences in albedo values at 1.08 and $1.59 \mu \mathrm{m}$. This could be due to differences in the grain sizes of 
the mixture components and/or could be related to the age difference between Selk and Santorini/Guabonito. Selk appears to be of intermediate degradation state according to its depth (Neish et al. 2018) and emissivity (Werynski et al. 2019).

There is a marked difference in the component abundances in the surface mixtures between the crater floors and the ejecta blankets in the dune craters, as shown from the VIMS analysis. This is not consistent with the emissivity values, which are similar for both units, except for Selk crater for the reasons discussed above. For Ksa, Santorini, and Guabonito, the albedo and emissivity values of the crater floors point to an organic nature in the top and near surface composition, suggesting infilling by an organic component such as sand or liquids (Werynski et al. 2019). The dark material is prominent in the craters floors in contrast to the ejecta blankets, which are richer in tholins, suggesting more dune material is being deposited on the crater floors. The presence of tholins in the ejecta blankets could be due to the chaotic mixing that takes place during the impact process, and/or more atmospheric depositions in the ejecta blankets due to topography.

\subsection{The plain craters}

The plain craters are classified as intermediate (Forseti, Afekan) or old (Soi) in age based on their relative depths (Neish et al. 2018). Unlike most of the dune craters, they have water ice in their mixtures, with $\sim 15-20 \%$ in their craters floors and $\sim 10$ $30 \%$ in their ejecta blankets. This suggests a mixture of water ice and organics is being exposed by the craters, and kept relatively "clean" of sediment in the topmost layer of the surface. The emissivity values from both floor and ejecta units agree with this interpretation, and suggest subsequent infill by organic-rich sediments as the craters become more degraded. Forseti's ejecta blanket has an emissivity value of 0.83 , suggesting water ice enrichment, while its floor has an emissivity value of 0.93 , consistent with a mixture of organics and water ice. The more degraded craters - Afekan and Soi - have higher emissivity values in both their ejecta and floors, suggesting subsequent infill by organics.

As we describe above, the composition of the crater floors and ejecta blankets differs for the dune craters, but are generally the same for the plain craters. The dune craters have more dark material in their crater floors, likely consistent with infill by dark organic sand sediment through aeolian processes. The plain craters, in contrast, have similar component abundances in both their floors and ejecta blankets. It is possible there is less erosion and weathering occurring in the plains, and the plain craters represent what less degraded craters on Titan should look like, explaining the similarity in the spectral response of the ejecta and floors. However, the shallow depths of the craters suggest that erosion is occurring, and the emissivity results suggest that organic infill is occurring in the subsurface. Thus, we speculate (as in Werynski et al. 2019), that some process (possibly fluvial in nature) is causing the surfaces of the plain craters to be periodically "cleaned" of any surficial material over time. This is supported by the range of relative depths of the craters in the plains, suggesting different degrees of fluvial erosion (Neish et al. 2016; Hedgepeth et al. 2020). It is also possible that the organics covering the plains are not the same in composition or in size as the ones covering the dunes.

\subsection{Proposed scenario for landscape evolution on Titan}

Our results are partially in agreement with the results presented in Werynski et al. (2019). We see similar compositions between the crater floors and ejecta blankets in the plains, consistent with the hypothesis by Werynski et al. (2019) that an active process (like fluvial erosion) is "cleaning" the surfaces of the craters of atmospheric deposits of organic materials. However, in our RT and compositional analysis, there is no evidence of water ice in the dune craters, with the exception of Sinlap. This suggests that the "cleaning" process does not operate in the dunes, but rather there is a complete resurfacing of the craters due to aeolian processes, at least in the very top layers of the surface. This process appears to occur quite rapidly, with even morphologically fresh craters, like Ksa and Selk, apparently covered by a thin layer of organic material. This suggests the dunes (or other mobile materials such as dusts of finer particles) are presently active, and not fossilized from an earlier time in Titan's history.

As mentioned above, the plain craters are more enriched in water ice than the dune craters. The presence of water ice may suggest that these craters formed in a region with less organics than the dunes, as suggested in Werynski et al. (2019), or it may point to the rapid resurfacing of the dune craters by organic sand. We favor the latter explanation, because Sinlap has a similar composition to the plain craters, despite being located in the Fensal sand sea. The Sinlap blanket ejecta is the only unit that appears to be enriched in some long-chain organic ice like $\mathrm{CH}_{4}$, similarly to the Afekan crater ejecta, which is a typical plains crater. In this way, Sinlap presents an example of a "fresh" crater, originally composed of a mixture of water ice and organics, while the other dune craters demonstrate what happens to these craters as they age, most likely building a thin layer of sand on the ejecta while the crater floors also fill up with sand. The plain craters, on the other hand, retain their "fresh" spectral response due to fluvial erosion or slow aeolian sediment transport.

The observed enrichment in organics in the dune craters and the enrichment in water ice in the plain craters also agrees with the results by Solomonidou et al. (2018). In that work, it was proposed that there is a compositional latitudinal dependence on Titan. In that study, the undifferentiated plains of the midlatitudes were found to be enriched in water ice, while the equatorial ones are abundant in organics. The craters that are close to $30^{\circ} \mathrm{N}$ and the midlatitudes such as Afekan, Soi, Menrva, and Forseti (Fig. 1) seem to represent one regime as they share similar compositional as well as emissivity characteristics (0.83-0.95). Their main constituent is the tholin-like organic material, while there is also a significant abundance of water ice and less of the dark material compared to the dune craters. The craters in the equatorial dunes seas such as Ksa, Selk, Santorini, and Guabonito have compositions which appear purely organic for both floor and ejecta units, except for Selk's ejecta blanket. Lastly, Sinlap seems to have a unique "identity." Its very young age makes it compositionally different than expected from its geographic location. Over time, we speculate that Sinlap will appear more similar to the other dune craters, as sand covers over its original composition, which was generated during the impact itself. Hence, both erosion and geographic location appear to play a role in the composition of the craters.

\section{Conclusions}

In this work, we suggest that there are two classes of impact craters on Titan: those found in the equatorial dunes, and those found in the midlatitude plains. The results show that the equatorial dune craters appear to be purely composed of organic material (mainly an unknown dark material). The midlatitude plain craters, on the other hand, in addition to the special cases of 
Menrva and Sinlap, are enriched in water ice, within an organicbased mixture, along with a small amount of ice containing other organic molecules with $\mathrm{CH}_{3}, \mathrm{CH}_{2}$, and $\mathrm{CH} \mathrm{C}-\mathrm{H}$ bonds in some cases. This follows the pattern seen in Solomonidou et al. (2018), where midlatitude alluvial fans, undifferentiated plains, and labyrinths were found to consist of a tholin-like and water ice mixture, while the equatorial undifferentiated plains, hummocky terrains, dunes, and variable plains were found to consist of a dark material and tholin-like mixture in their very top layers. We found no indication for the presence of either $\mathrm{NH}_{3}$ or $\mathrm{CO}_{2}$ ice in the craters, but in future we need to include other organic molecules in the spectral mixing models, such as those containing $\mathrm{CH}_{3}, \mathrm{CH}_{2}$, and $\mathrm{CH} \mathrm{C}-\mathrm{H}$ bonds with carbon in $\mathrm{sp}^{3}, \mathrm{sp}^{2}$, and sp hybridization states, to explore their presence on Titan.

These observations agree with the evolution scenario proposed by Werynski et al. (2019), wherein the impact cratering process produces a mixture of organic material and water ice, which is later "cleaned" through fluvial erosion in the midlatitude plains. However, the cleaning process does not appear to operate in the equatorial dunes; rather, the dune craters are quickly covered by a thin layer of sand sediment. This scenario agrees with other works that suggest that atmospheric deposition is similar in the low-latitudes and midlatitudes on Titan, but with more rain falling onto the higher latitudes causing additional processing of materials in those regions (Neish \& Lorenz 2014; Neish et al. 2016; Solomonidou et al. 2018). In either case, it appears that active processes are working to shape the surface of Titan, and it remains a dynamic world in the present day. This is a hypothesis that will be tested by the Dragonfly mission, which aims to investigate the crater Selk during its prime mission, and identify the products of interaction between water (which was liquid at the time of impact) and organics (Turtle et al. 2020).

Acknowledgements. All Cassini data used in this article can be accessed in the Planetary Data Systems (PDS). The authors would like to thank Dr. Bernard Schmitt for his helpful advice on various issues examined in this work. This research was partly supported by the NASA Astrobiology Institute through its JPL-led project entitled Habitability of Hydrocarbon Worlds: Titan and Beyond. This research was partly supported by the Cassini Data Analysis and Participating Scientists Program (CDAPS) grant \#NH16ZDA001N to R.L. A.S. is supported by a European Space Agency (ESA) Research Fellowship at the European Space Astronomy Center (ESAC), in Madrid, Spain. A.S., A.C., and P.D. acknowledge support from the CNES Appel annuel à Propositions de Recherche Program. Y.M. is supported by the Czech Science Foundation (grant no. 20-27624Y). This work was partly conducted at Jet Propulsion Laboratory (JPL) and the California Institute of Technology (Caltech) under contract with NASA. (C) 2020 California Institute of Technology. Government sponsorship acknowledged.

\section{References}

Bernard, J.-M., Quirico, E., Brissaud, O., et al. 2006, Icarus, 185, 301 Boudon, V., Rey, M., \& Loëte, M. 2006, J. Quant. Spec. Radiat. Transf., 98 394
Brassé, C., Muñoz, O., Coll, P., et al. 2015, Planet. Space Sci., 109, 159 Brown, R. H., Baines, K. H., Bellucci, G., et al. 2004, Space Sci. Rev., 115, 111 Buratti, B. J., Sotin, C., Lawrence, K., et al. 2012, Planet. Space Sci., 60, 18

Campargue, A., Wang, L., Mondelain, D., et al. 2012, Icarus, 219, 110

Campargue, A., Segovia, J. L., Béguier, S., et al. 2015, J. Quant. Spec. Radiat. Transf., 152, 140

Crosta, A. P., Silber, E. A., Lopes, R. M. C., et al. 2019, LPI Contributions, 2136, 5015

de Kok, R., Irwin, P. G. J., Teanby, N. A., et al. 2007, Icarus, 186, 354

Evans, K. F. 2007, J. Atmos. Sci., 64, 3854

Fulchignoni, M., Ferri, F., Angrilli, F., et al. 2005, Nature, 438, 785

Hedgepeth, J. E., Neish, C D., Turtle, E. P., et al. 2020, Icarus, 344, 113664

Hirtzig, M., Bézard, B., Lellouch, E., et al. 2013, Icarus, 226, 470

Janssen, M. A., Le Gall, A., Lopes, R. M., et al. 2016, Icarus, 270, 443

Lafferty, W. J., Solodov, A. M., Weber, A., et al. 1996, Appl. Opt., 35, 5911

Lellouch, E. 2006, Science, 311, 186

Le Mouélic, S., Paillou, P., Janssen, M. A., et al. 2008, J. Geophys. Res. Planets, 113, E04003

Le Mouélic, S., Cornet, T., Rodriguez, S., et al. 2019, Icarus, 319, 121

Lopes, R. M. C., Malaska, M. J., Solomonidou, A., et al. 2016, Icarus, 270, 162

Lopes, R. M. C., Wall, S. D., Elachi, C., et al. 2019, Space Sci. Rev., 215, 33

Lopes, R. M. C., Malaska, M. J., Schoenfeld, A. M., et al. 2020, Nat. Astron., 492, 4, 228-33

Lorenz, R. D., Wood, C. A., Lunine, J. I., et al. 2007, Geophys. Res. Lett., 34 L07204

Malaska, M. J., Lopes, R. M. C., Williams, D. A., et al. 2016, Icarus, 270, 130

Malaska, M. J., Radebaugh, J., Lopes, R. M. C., et al. 2020, Icarus, 344, 113764

McKellar, A. R. 1989, Icarus, 80, 361

Melosh, H. J. 1989, Impact cratering: A geologic process (Oxford, UK: Oxford University Press)

Neish, C. D., \& Lorenz, R. D. 2012, Planet. Space Sci., 60, 26

Neish, C. D., \& Lorenz, R. D. 2014, Icarus, 228, 27

Neish, C. D., Lorenz, R. D., Kirk, R. L., et al. 2010, Icarus, 208, 385

Neish, C. D., Kirk, R. L., Lorenz, R. D., et al. 2013, Icarus, 223, 82

Neish, C. D., Barnes, J. W., Sotin, C., et al. 2015, Geophys. Res. Lett., 42, 3746

Neish, C. D., Molaro, J. L., Lora, J. M., et al. 2016, Icarus, 270, 114

Neish, C. D., Lorenz, R. D., Turtle, E. P., et al. 2018, Astrobiology, 18, 571

Niemann, H. B., Atreya, S. K., Demick, J. E., et al. 2010, J. Geophys. Res. Planets, 115, E12006

Rey, M., Nikitin, A. V., Bézard, B., et al. 2018, Icarus, 303, 114

Soderblom, L. A., Tomasko, M. G., Archinal, B. A., et al. 2007 , Planet. Space Sci., 55, 2015

Solomonidou, A., Hirtzig, M., Coustenis, A., et al. 2014, J. Geophys. Res. Planets, 119, 1729

Solomonidou, A., Coustenis, A., Hirtzig, M., et al. 2016, Icarus, 270, 85

Solomonidou, A., Coustenis, A., Lopes, R. M. C., et al. 2018, J. Geophys. Res. Planets, 123, 489

Solomonidou, A., Le Gall, A., Malaska, M. J., et al. 2020, Icarus, 344, 113338

Sotin, C., Jaumann, R., Buratti, B. J., et al. 2005, Nature, 435, 786

Tomasko, M. G., Archinal, B., Becker, T., et al. 2005, Nature, 438, 765

Tomasko, M. G., Doose, L., Engel, S., et al. 2008, Planet. Space Sci., 56, 669

Turtle, E. P., Trainer, M. G., Barnes, J. W., et al. 2020, LPSC, 2288

Werynski, A., Neish, C. D., Gall, A. L., et al. 2019, Icarus, 321, 508

Wood, C. A., Lorenz, R., Kirk, R., et al. 2010, Icarus, 206, 334 